\title{
Industrial Symbiosis Implementation Potential-An Applied Assessment Tool for Companies
}

\author{
João Azevedo ${ }^{1}$, Inês Ferreira ${ }^{1, *}$, Rui Dias ${ }^{1}\left(\mathbb{D}\right.$, Cristina Ascenço ${ }^{2}\left(\mathbb{D}\right.$, Bruno Magalhães $^{3}$, Juan Henriques ${ }^{1} \mathbb{D}$, \\ Muriel Iten ${ }^{1}$ and Fernando Cunha ${ }^{4}$ \\ 1 Low Carbon \& Resource Efficiency, R\&Di, Instituto de Soldadura e Qualidade, 4415-491 Grijó, Portugal; \\ jdazevedo@isq.pt (J.A.); radias@isq.pt (R.D.); jdhenriques@isq.pt (J.H.); mciten@isq.pt (M.I.) \\ 2 Programs and Business Incubation, R\&Di, Instituto de Soldadura e Qualidade, 2740-120 Oeiras, Portugal; \\ cgascenco@isq.pt \\ 3 Low Carbon \& Resource Efficiency, R\&Di, Instituto de Soldadura e Qualidade, 2740-120 Oeiras, Portugal; \\ brodmagalhaes@isq.pt \\ 4 Escola Superior de Tecnologia de Setúbal-Instituto Politécnico de Setúbal, 2910-761 Setúbal, Portugal; \\ fernando.cunha@estsetubal.ips.pt \\ * Correspondence: irferreira@isq.pt; Tel.: +351-915-428-335
}

check for updates

Citation: Azevedo, J.; Ferreira, I.; Dias, R.; Ascenço, C.; Magalhães, B.; Henriques, J.; Iten, M.; Cunha, F. Industrial Symbiosis Implementation Potential-An Applied Assessment Tool for Companies. Sustainability 2021, 13, 1420. https://doi.org/ $10.3390 /$ su13031420

Academic Editor: Tiberio Daddi

Received: 18 December 2020

Accepted: 27 January 2021

Published: 29 January 2021

Publisher's Note: MDPI stays neutral with regard to jurisdictional claims in published maps and institutional affiliations.

Copyright: (c) 2021 by the authors. Licensee MDPI, Basel, Switzerland. This article is an open access article distributed under the terms and conditions of the Creative Commons Attribution (CC BY) license (https:// creativecommons.org/licenses/by/ $4.0 /)$.

\begin{abstract}
A successful and broad implementation of industrial symbiosis (IS) initiatives is highly related to stakeholder's involvement and technical considerations on its process' development. This paper presents a mixed research study (quantitative and qualitative) focusing on the development of a dedicated tool based on sequential modules' that support companies in the assessment of their potential to develop and implement IS scenarios. The first module considers the identification and characterization of the economic activity of the company to support an IS contextualization analysis. The second module provides the evaluation of the company's current state, allowing key intervention areas to be defined. The third module focuses on the assessment of the potential scenarios for synergies implementation based on an economic benefit comparison of different valorization scenarios regarding the available surplus or waste. Complementarily, a SWOT analysis for the identification of the internal strengths and weaknesses, the external opportunities and threats associated with the IS process implementation is presented. The final output compiles qualitative and quantitative results regarding each module. The presented tool is currently under validation at industrial case studies. The preliminary results show the high applicability of the proposed tool in order to support decision making processes on surpluses valorization scenarios selection.
\end{abstract}

Keywords: industrial symbiosis; current state assessment; implementation potential; waste valorization; decision support tool

\section{Introduction}

Industrial Symbiosis (IS), a sub-field of Circular Economy (CE), promotes numerous connections between companies (so-called synergies), mostly located with physical proximity to one another, to exchange materials, energy, infrastructures, knowledge, and services to promote mutual environmental, social, and economic benefits [1]. Symbiotic exchange can also happen within the same enterprise, among different processes, where the surpluses are valorized internally.

IS is one of the basic premises of Circular Economy, to create a circular system that envisages to incorporate the surplus from one industry into the production cycle of another industrial process as a substitute for raw materials, with the result of keeping resources in productive use for longer periods [2]. The application of IS mitigates the footprint of the involved industries, the magnitude of its production impacts, and waste disposal costs [3].

In the last decade, there has been an increase in the number of studies concerning the CE practices and IS implementation tools [4]. Considering the proven benefits and 
the potential of IS, it is crucial to stimulate its implementation to foster sustainable development for the industry [5]. Nevertheless, there is a set of intervening factors, that can work as barriers that restrict, or as enablers that foster the IS implementation at a large scale [6]. Islam [7], Golev et al. [6], and Doroteya et al. [8] have identified several industrial symbiosis barriers, which could be technological, economic and financial, lack of information, absence of trust among organizations, lack of commitment with sustainable development, regulatory (laws and regulation), and risk and uncertainty. On the other hand, in line with the dismissal of hindrances, a system of incentives is considered as an encouragement to facilitate the IS implementation for communities, companies, and entities $[9,10]$.

To overcome the technical/technological barriers, which plays a major role in advancing IS and CE implementation [8], several methods and tools have been reported in the literature [11]. Moreover, a great number of tools are relevant to boost the CE, for example: process modelling tools and methods, that can help mathematize, simulate and optimize conditions of industrial systems and identify potential resources to be linked [12]; mapping of industries and potential users [13]; optimize networks of resource exchanges [14]; applying Lean in the waste management to optimize the process [15]; and assess the environmental, economic and social impacts of synergies [14,16-21]. Moreover, Sustainable Consumption and Production (SCP) tools provide a set of methods and guides to support companies move to a more sustainable consumption and production [22], for example, Product Environmental Footprint (PEF) and Environmental Management System (EMS) can support companies in the identification of strategies and scenarios for waste valorization [4].

Looking exclusively at IS, in the last years it is noticeable the tendency to develop Information and Communication Technology (ICT) based tools that function as a platform embedding recommender systems, facilitating the matchmaking and mimicking of synergies [23], emerging as a result of research and innovation funding or private developments [24,25]. So far, IS tools have been developed responding to five fundamental stages: preliminary assessment, engage business, find synergy opportunities, determinate feasibility, implement transactions and documentation. This characterization of areas has been an adapted result of several studies developed on this subject [25]. The literature suggests that most of IS tools developed are concentrated in identifying opportunities/synergies and synergy assessment [23]. According to the same study, the preliminary assessment phase is driven from a top-down perspective, and no study was found to assess the preliminary conditions or the potential of a company to engage in IS.

The concept of IS potential is referred to by scholars in a broad sense and is usually assessed for Eco-Industrial Park developments or at a regional scale by identifying wastes to be exchanged and by mapping of surrounding industries [11,18]. This analysis of potential is complemented, in a triple-bottom analysis, with the assessment of the potential impacts and benefits, gained through the implementation of IS, per synergy, or as a total of a site/region. However, there is also an opportunity to assess the preliminary conditions at a company level, and not only at a site or regional level. Therefore, the concept of IS potential, as described in this paper, is explored in the view of analysing the preliminary conditions to engage in IS.

In this alignment the aim of this paper is to present a tool that support companies in assessing their potential to partake in IS activities. This potential assessment combines the evaluation of the company's current state regarding its performance in monitoring raw materials and surplus flows, the identification of surplus management practices including disposal and IS processes in case of existence, and the identification and comparison of the most valuable scenario for surplus valorization based on an economic perspective. Finally, a complementary identification of the company's strengths, weaknesses, opportunities and threats that might positively or negatively influence the symbiotic process implementation is performed by a SWOT analysis to support the overcoming of barriers and enhancing the enablers for IS activities implementation. 
The paper is divided into 4 sections. Section 1 presents the context of the present work, the intended goals, and a literature review. Section 2 describes the methodological approach of this work and an overview. In Section 3 a detailed description of the tool modules and applications are presented. Section 4 discusses the practical relevance of the tool and the current limitations. Finally, Section 5 summarizes the main conclusions drawn from the developed work.

\section{Methodological Approach and Overview}

\subsection{Methodological Approach}

The tool that is presented in this paper has been developed within the scope of a dedicated study [26], aiming to develop methodologies and tools to identify and evaluate the potential for IS, at intra and inter-company levels, as well as promote strategies for its implementation at large scale, generating economic, environmental and social benefits.

This tool follows the gap identified in the introductory section, regarding the lack of a preliminary IS assessment tool at a company level, and a need for an action plan demonstrated from the involved stakeholders in the study. The methodological approach, presented in Section 3, was so designed for an industrial application to cover any sector and any existing surplus. Moreover, it has been designed to include complementary tools and dedicated studies regarding materials (surplus) specificities and industrial sectors requirements that can facilitate the identification of alternative scenarios for its application [3].

In the alignment of the previous developments in the study, the literature review, and the interaction with the stakeholders, a sequential methodology was created based on the company's economic, geographical and environmental characteristics, the current state of the company on monitoring the materials and surplus flows, the actual management scenarios and destinations, the type of surplus originated in the industrial process, the economic value of its valorization, and the internal and external factors that could influence the IS implementation process. Thus, the methodology is composed of an assessment tool that facilitate decision-making processes, through an analysis of the current state of the company (present) and an evaluation of their potential for IS implementation (future).

The innovative aspect of this tool is the ability to identify and diagnose the company performance in relation to resource flows and symbiotic practices and enhance the implementation of IS activities by the identification and prioritization of valorization scenarios of the surplus, generating economic and environmental benefits for the company.

\subsection{Overview}

An important reinforcement to the gap has also been identified through a literature review on ways to assess companies through a maturity level, decision-support tool, and SWOT analysis regarding the IS practices.

Usually, companies resort to maturity models/tools to evaluate the current state of their company in diverse areas $[27,28]$. A maturity model attends as a guide for the company, allowing the organization to identify its behavior in different areas, in order to maximize its performance [29]. With the advancement of studies on this theme, several models evaluating maturity levels have been disseminated. These models are applied in different industrial fields and in general, are associated with business demands to improve project management [30,31], supply chain management [32], among others. Barra et al. [29] has done a review on multiple maturity models and it is possible to verify that none is focused on the maturity of the company's materials flows and associated management practices including IS. Golev et al. [6], however, has developed a tool that helps monitoring and assesses the level of maturity of potential industrial cooperative initiatives, involving various stakeholders. The maturity assessment includes seven IS barriers that are tested against five stages of maturity, to evaluate the collaboration between companies in the same region. The same study defends that the maturity assessment of a company can identifies the barriers and enablers for synergy opportunities allowing the improvement 
of IS implementation. Besides this study, from the authors search, no other maturity assessment tool focused on the implementation of IS has been encountered in the literature.

Another important step towards unblocking the IS implementation is the support in the stakeholder's decision-making regarding the surplus valorization alternatives, due to the high level of uncertainty of the economic and environmental benefits related to the synergies [8]. Several decision support tools have been analyzed by Neto et al. [33] and each one differs concerning their purpose, methodology, final product, and relevance for an analysis from the company perspective. Neves et al. [11] identifies various methodologies to analyses the potential of a synergy, such as interviews, questionnaires, site visits, and focus groups, to study the best way to establish a symbiotic practice regarding the most promising waste streams and the companies with the highest potential for integration. Further assessment on the potential impacts of IS implementation in the environment, in the companies involved, and in the society is considered. The most applied method was based on the use of environmental indicators, the reduction of carbon dioxide emissions, the quantification of savings in the consumption of resources, such as energy, water, raw materials, and fossil fuels, and the reduction of waste sent to landfills. Moreover, the economic aspect, is also evaluated and is measured using life cycle costing (LCC) method and several metrics which reflects reductions in resources consumption and waste disposal costs, and consequently increase revenues. Besides these methods, Lutje et al. [34] confirmed that no dedicated decision support tool regarding the economic viability of different IS activities was found. Although the development of frameworks and tools are being produced to support stakeholder's on decision making processes, most of those tools are not available publicly, were not validated, and most of times when associated to project funding they are no longer used after project ends [35].

To complement the final decision making, it is important to identify the internal and external factors that can influence the company in the IS process implementation. Thus, the SWOT analysis, commonly used, is considered as a strategic tool for gathering and organizing the information needed to evaluate the positive and negative factors of an organization [36]. To achieve a successful strategy, the organization should focus on strengths and opportunities, and try to handle weaknesses, avoiding threats [37]. There are numerous developments by companies in doing SWOT analysis but rarely targeted in symbiotic practices.

In the next section, the characterization of the variables that define the possible interactions of industrial surplus and its valorization as well as the three modules of the tool are explained in detail.

\section{Tool for Industrial Symbiosis}

\subsection{Material Flows and Valorization Options}

To support the development of this tool is necessary to identify and characterize the full spectrum of company's operations regarding the inputs and outputs of materials, current management practices, and alternatives for the surplus valorization. Figure 1 summarize the potential material flows of Input Raw Materials and Surplus (wastes and by-products), as well as the possible destinations for the surpluses, including Disposal, Recovery/Recycling, and IS practices (Intra IS, Inter IS). 


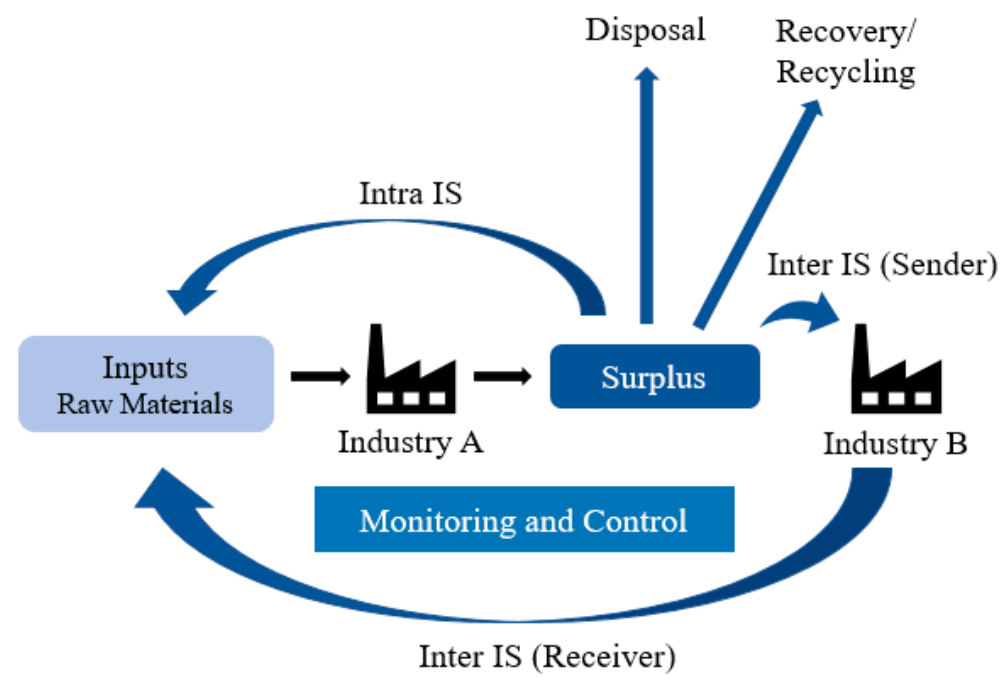

Figure 1. Materials and surplus flow scheme options.

All the variables illustrated in Figure 1 are further described in Table 1.

Table 1. Definition of the materials flows and valorization options.

\begin{tabular}{cl}
\hline Variables & \multicolumn{1}{c}{ Description } \\
\hline Input Raw Material & $\begin{array}{l}\text { It refers to the raw materials that enter in a company to be } \\
\text { introduced in the productive process }\end{array}$ \\
\hline Surplus & $\begin{array}{l}\text { It refers to one of the outputs of the productive process, that does } \\
\text { not correspond to the final product. It can include materials } \\
\text { (residues, wastes and by products), energy, heat, or water, which } \\
\text { has not added value for the company }\end{array}$ \\
\hline Disposal & $\begin{array}{l}\text { It refers to situations when a surplus is not valorized and it is } \\
\text { eliminated, for example, sent to a landfill }\end{array}$ \\
\hline Recovery/Recycling & $\begin{array}{l}\text { It refers to the set of operations that allow the reutilization of the } \\
\text { surplus and obtain similar materials }\end{array}$ \\
\hline Intra IS & $\begin{array}{l}\text { The surplus is valorized internally in the company, which could } \\
\text { take part in the process that originates the surplus or other internal } \\
\text { production processes }\end{array}$ \\
\hline Inter IS-Sender & The surplus is valorized externally by another company \\
\hline Inter IS-Receiver & $\begin{array}{l}\text { The surplus from other industries is introduced in the company to } \\
\text { be incorporate as an input of a certain process }\end{array}$ \\
\hline & $\begin{array}{l}\text { This process was found to be transversal and applied to all the } \\
\text { identified scenarios across the company allowing to evaluate and } \\
\text { monitor their performance by collecting information during } \\
\text { all phases }\end{array}$ \\
\hline Monitoring and Control
\end{tabular}

Industrial Processes often use raw materials as input for their production processes. Besides the main product, the production process often originates surpluses, which can be materials, energy, heat, and water that cannot be further valorized throughout the process. Once the surplus is derived, the company is responsible for its management. One of the possible scenarios is the disposal of the surplus in landfills or sending it to be eliminated, which causes economic losses due to the valuable materials that are not recovered and negative environmental impacts. Therefore, rather than disposal, the surplus can be redirected to serve different alternatives of valorization, being associated with positive environmental impacts and economic wise. Such alternatives of valorization could be associated to surplus recycling, the internal reutilization of the surplus in the company, or the reutilization of the surplus by other companies. The destination for surplus valorization 
relies on numerous factors, such as the surplus characteristics, its market value, and its applicability in a productive process to substitute the virgin raw materials.

Overall, such alternatives of valorization, avoid the disposal of surplus into landfill and take advantage on the exploitation of an uncaptured value surplus at its end of life by industries.

\subsection{Tool for Industrial Symbiosis Potential}

The tool to be presented has been established to support companies with the IS implementation process, through: the company's identification (Module A), the evaluation of its current state in monitoring the inputs and outputs materials flow, their disposal management practices, and the actual surplus valorization by IS, when applicable (Module B), and the comparison of the different surplus valorization scenarios, and the identification of the internal and external factors that influence the implementation of IS practices at company level (Module C). This tool comprehends the three aforementioned independent and sequential modules. For that, it has been necessary to determine several variables to define each module and consequently support the company for further IS implementation. The modules have been designed to gather explicit information, to further retrieve quantitative and qualitative results about the context and conditions for IS implementation. Figure 2 summarizes the key features in each module.

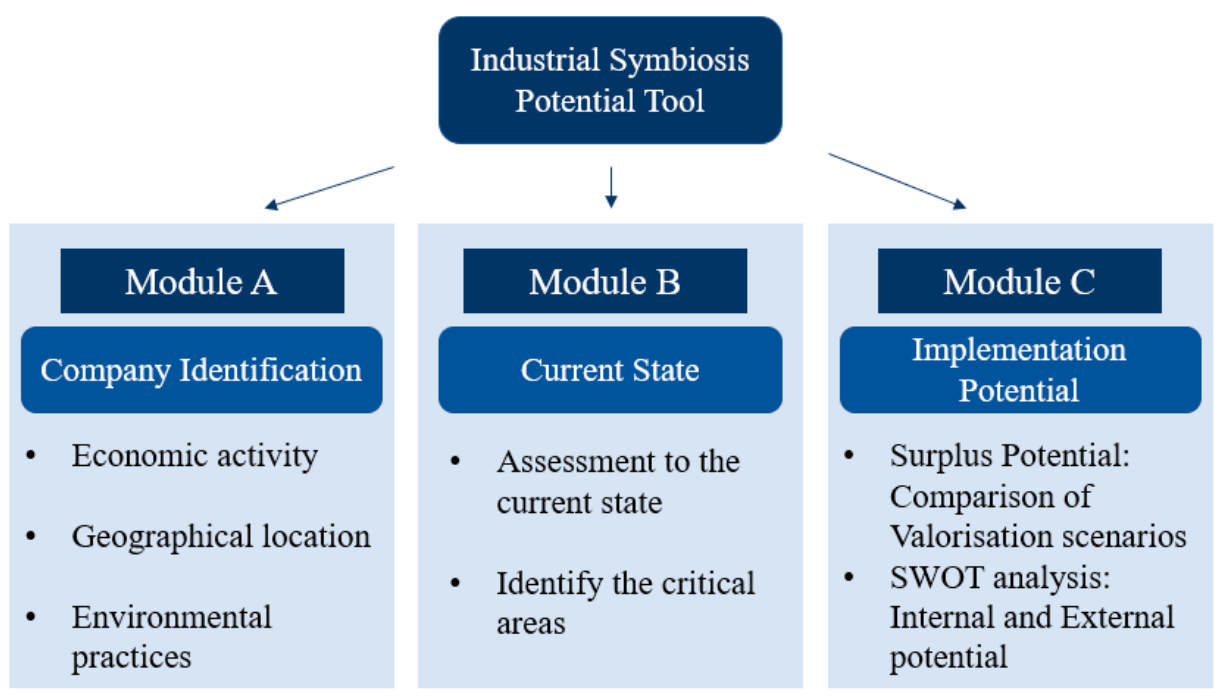

Figure 2. Industrial symbiosis potential tool modules structure.

Module A includes the identification and characterization of the economic activity, geographical location and environmental practices of the company in order to support IS contextualization analysis. Module B provides the evaluation of the company's current state in monitoring the materials and surpluses flows and destination, allowing to identify and define the key intervention areas. Finally, Module $C$ focuses on the assessment of the potential scenarios for synergies implementation. It consists of an economic benefit comparison of different valorization scenarios regarding the available surpluses, as well as a SWOT analysis for the identification of the internal and external potential. A full detailed description of the variables, the scope, and the expected results of each module is presented in the next sub-sections.

\subsubsection{Module A-Company Identification}

To characterize and contextualize the company, a questionnaire was formulated based on five fields, which is presented in Table 2. Those fields include the classification of economic activities (CAE) to define the productive activity; the number of employees and the annual turnover to characterize the size of the company; the company location 
to analyze its industrial context; and the environmental management system to identify existing environmental practices.

Table 2. Questionnaire for the Company's Identification.

\begin{tabular}{|c|c|c|}
\hline Fields & Technical Objective & Question \\
\hline Economic Activities & Define the productive activity & $\begin{array}{l}\text { Which economic activity is the } \\
\text { company inserted? }\end{array}$ \\
\hline $\mathrm{N}^{\circ}$. Employees & Characterize the size of the company & $\begin{array}{l}\text { How many employees does the } \\
\text { company have? }\end{array}$ \\
\hline Annual Turnover & Characterize the size of the company & $\begin{array}{l}\text { How much is the annual turnover of } \\
\text { the company? }\end{array}$ \\
\hline Company Location & Analyze the Industrial Context & Where is the company's location/address? \\
\hline Company Location & Analyze the Industrial Context & Is the company settled in an industrial park? \\
\hline Environmental Management System & Identify Existing Environmental Practices & $\begin{array}{l}\text { Does the company have implemented an } \\
\text { environmental management system? }\end{array}$ \\
\hline
\end{tabular}

The questionnaire includes straight forward information to simplify the approach towards the user, and a close-ended answer should be given for each field. The information gathered in this module supports the viability of the IS potential scenarios implementation.

\subsubsection{Module B-Current State}

An evaluation of the company's current state regarding the materials and surpluses management is to be performed. It allows the company to identify its behavior in different areas, by monitoring its actual practices regarding materials and surpluses flows and destinations. It also analyses if there is any sort of existence of IS practices within the company. It permits the company understanding its behavior in monitoring the materials and surplus flows and destinations, to improve its management and identify opportunities for surplus valorization. Its determination is based on the seven areas identified in Table 3. These variables are assessed by the ability to control and monitor each of the defined areas. Following the same principles of module A, a set of questions have been defined, regarding the seven areas, that could be found in Table 3.

Table 3. Questionnaire for current state assessment.

\begin{tabular}{cl}
\hline Area & \multicolumn{1}{c}{ Question } \\
\hline Input-Raw Material & Does the company monitor the input materials' flows in its industrial process? \\
Surplus & Does the company monitor the surpluses resultant from its industrial process? \\
Disposal & Does the company send the surpluses to disposal? \\
Recovery/Recycling & Does the company send the surpluses to recovery / recycling? \\
Intra IS & Does the company recover internally any surplus from its industrial process? \\
Inter IS-Sender & Does the company send its surplus for another industry for valorization? \\
Inter IS-Receiver & Does the company receive any surplus resultant from another industry? \\
\hline
\end{tabular}

The current state is defined by a number, in a pre-defined numeric scale, from 0 to 1 , where 0 corresponds to a company that does not monitor any of its material flows, inputs and surpluses and do not have any industrial symbiosis practices implemented. While, 1 corresponds to a company that fully monitor all their inputs and outputs and has already implemented some sort of symbiotic exchanges. Thereby, within the obtained results, it is possible to identify the key intervention areas and consequently the ones less developed in the company. Following these assumptions, equation 1 allows to calculate the level of the company's current maturity state, which corresponds to the sum of the grades (0 to 1) associated to each area (listed in Table 3). From Equation (1), a quantitative result is attained, considering the same weight for each area. Thus, company's presenting a current state close to 0 present a great potential to implement industrial symbiosis practices. While, company's current state close to 1 corresponds to the ones already with some control in 
their practices, but still requiring a new/different destination and approaches to valorize their surpluses.

$$
\text { Current State }=\sum_{1}^{7} \% \text { Field } i \times \frac{1}{7}
$$

To each field of analysis, a five-answer scale was created to symbolize the various levels of monitoring, with a respective weight values associated as presented in Table 4 .

Table 4. Interpretation scale for maturity assessment.

\begin{tabular}{cc}
\hline Possible Answer & Weighting \\
\hline No, in any scenario & 0 \\
Yes, some of the materials/outputs in specific cases & 0.25 \\
Yes, all the materials/outputs in specific cases & 0.5 \\
Yes, some of the materials/outputs systematically & 0.75 \\
Yes, all the materials/outputs systematically & 1 \\
\hline
\end{tabular}

For all the fields this is the interpretation scale, except for the disposal, which is the opposite weighting scale, so if the answer is No, in any scenario the weighting is 1 , and if the answer is Yes, all the materials/outputs systematically the weighting is 0 .

The evaluation of the current state reports results could be easily interpreted by the company, and allows its revaluation in time, recording its evolution. The expected result can be read in a dashboard to easily identify and analyze its information. The proposed dashboard contains two visual graphs, as shown in Figure 3, which allow the identification of the priority areas for intervention.

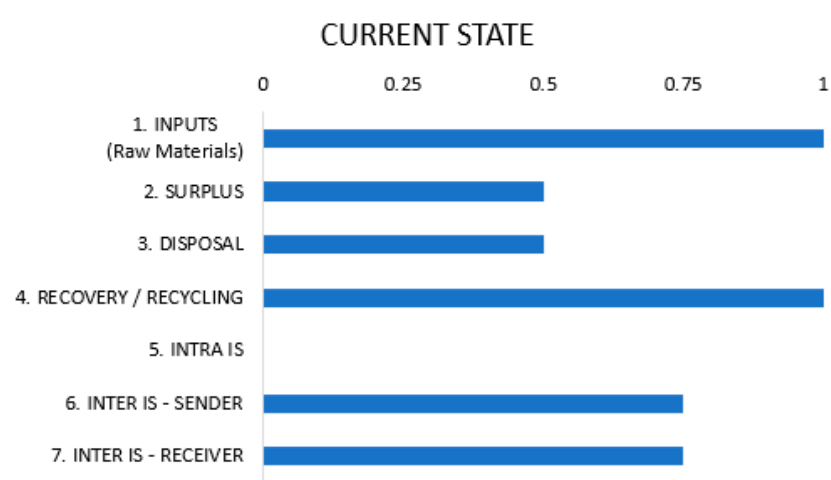

(a)

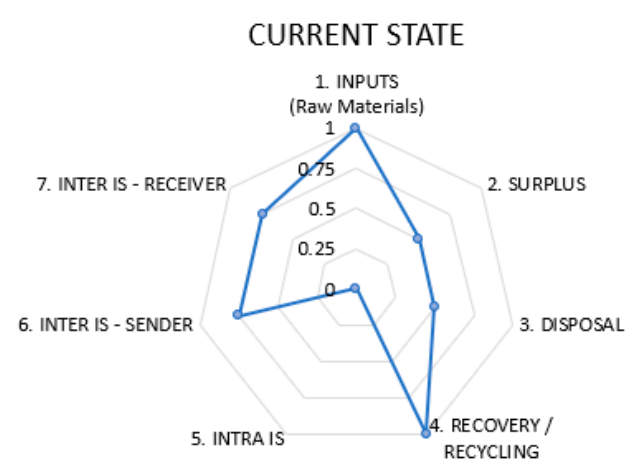

(b)

Figure 3. Example of a (a) bar graph and (b) radial graph of the current state level of the company's areas.

Once the company's current state is analyzed, the following module consists of assessing the implementation potential.

\subsubsection{Module C-Implementation Potential}

Module $\mathrm{C}$ is divided into two main sub-modules: the first one seeks to analyze the surplus potential based on the definition of its value, to further compare the alternative scenarios for surplus valorization. Secondly, and complementarily a SWOT analysis is performed based on internal and external factors that influence, positively and negatively, the IS implementation process. Figure 4 exemplifies the structure of module $C$ and the main objectives of each sub-module. 


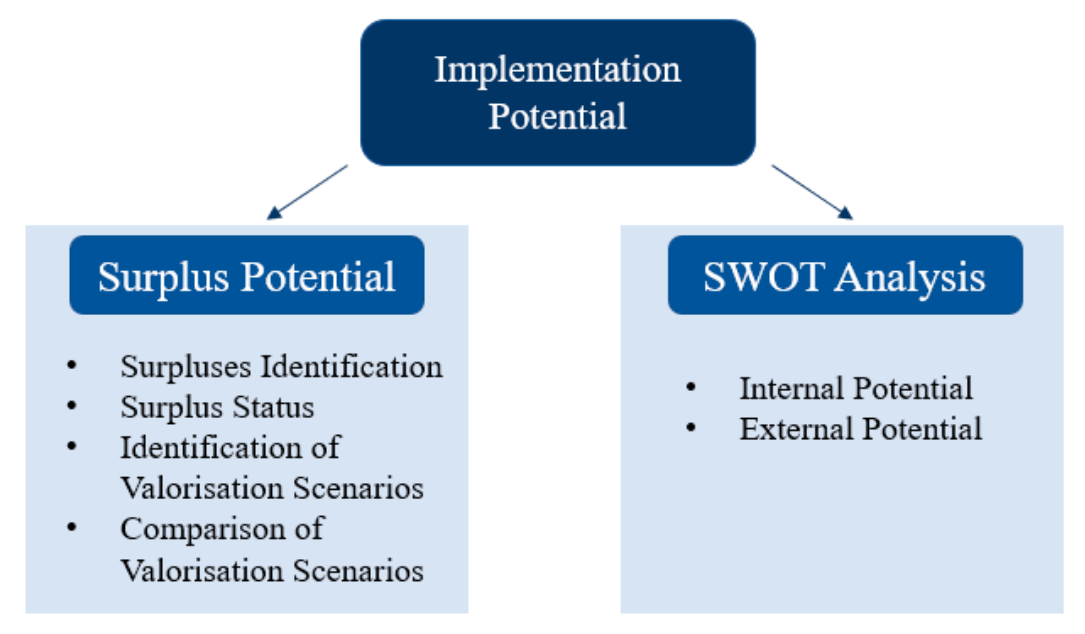

Figure 4. Implementation potential module.

Surplus Potential

The Surplus Potential evaluation is comprised by four sequential phases as shown in Figure 5 .

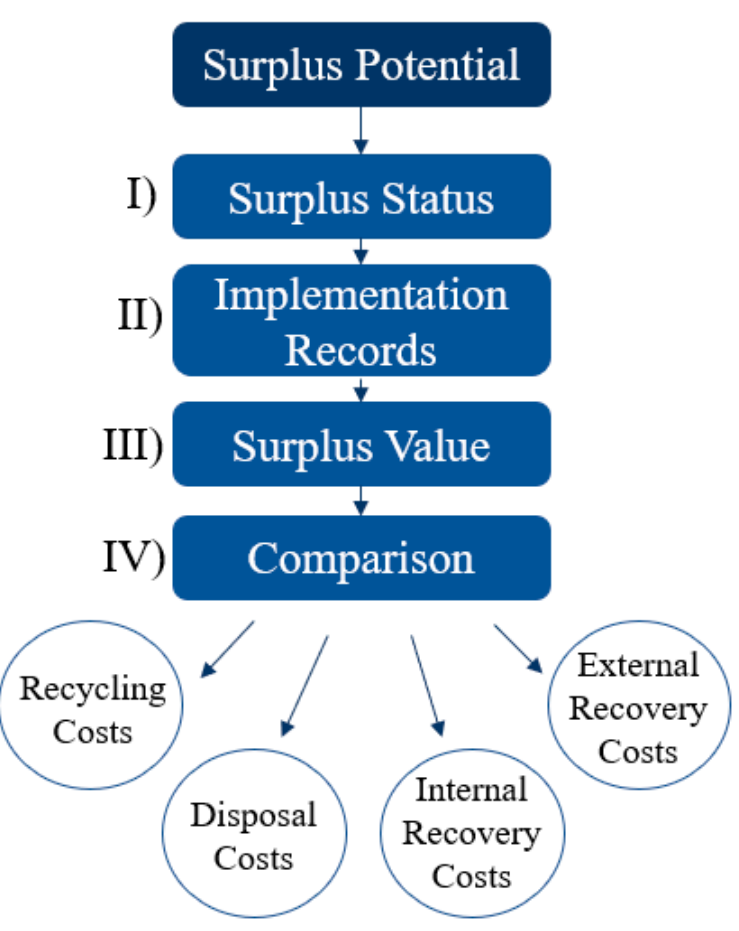

Figure 5. Surplus potential approach.

Phase (I) Surplus Status

In the first place, it is essential to evaluate the surplus status. Surplus materials assume the designation of either a by-product or a residue. If the surplus assumes the legal status of by-product it means that it does not correspond to the primary products of a production process but it can be used directly in the same or other industrial processes, according to the existing local legislation [38]. Otherwise, if the surplus is legally defined as a residue, it cannot be reintroduced in a production process, unless the waste is declassified, or the company has a permit to handle it. This generic approach allows a clear view on the first stage of the IS potential assessment.

Phase (II) Implementation Records

In this phase (II), the implementation records of the surplus applicability are investigated by identifying previous industrial practices that have already been implemented 
to this surplus. This research therefore consists at looking for previous sectorial or intersectoral synergies to enable the replicability for the valorization scenarios. Such analysis is highly related to existing databases (DB) where symbiotic exchanges are considered. ISDATA [39], SCALER technology database [40] and Maestri [41] are some examples of open databases. A dedicated methodology for the identification of implementation records of synergies and all the research process to valorize a surplus has already been settled by the authors in Dias et al. [42].

Phase (III) Surplus Value

Once the status and the synergies for the surplus are identified, the next step is to determine the surplus value (SV). This economic value includes all the costs and externalities involved in its production, for further comparison between valorization scenarios. The cost value can be acquired by different methodologies, for this study, an integrated approach with the methods of Material Flow Cost Accounting (MFCA) and Cross Media Effects has been adopted following Schmidt et al. [43]. Both methods consider the price of the raw material and all the resources involved in the production process, such as water, energy, heat, and skilled labor.

Phase (IV) Comparison

At last, in this phase, alternative scenarios for the surplus' valorization are compared, based on an economic perspective. For that, four main scenarios costs have been defined to structure, facilitate and support their comparison, namely: Disposal Costs (DC), Recycle Costs (RC), Internal Reutilization Costs (IRC), and External Reutilization Costs (ERC).

The proposed methodology compares each one of the pre-selected scenario costs in relation to a reference value cost (RVC). This RVC assumes a negative value as it considers the inherent resources spent during the production process together with the management costs associated to the treatment, transport, disposal or landfill of the surpluses (DC). In practice, the RVC is obtained from the sum of the surplus value (SV) previously calculated, and the disposal costs (DC). This generic approach has been selected as the baseline scenario for the comparison tool.

Regarding the considered valorization scenarios, they can represent an opportunity to minimize losses, or even represent an economic benefit for the company.

The recycling scenario can represent either an economic benefit if the surpluses can be sold or increase the company's losses if associated costs in the process occur. This fact is highly dependent on the exchanged material, its market value and legislative context. The internal reutilization scenario can actively promote economic benefits at company level, reducing costs by the substitution of raw materials (inputs), and consequently minimizing or eliminating the associated disposal costs. Regarding the external reutilization scenario, it refers to industrial symbiosis practices. These can promote economic gains, through selling the surplus to other companies, or minimizing company losses by the reduction of the disposal costs.

To find the best valorization scenario, it is necessary to individually calculate the difference between their associated costs and the RVC, which are represented in Equations (2)-(4), respectively.

$$
\begin{aligned}
\Delta 1 & =\text { RVC }- \text { RC } \\
\Delta 2 & =\text { RVC }- \text { IRC } \\
\Delta 3 & =\text { RVC }- \text { ERC }
\end{aligned}
$$

where $\Delta$, represents the economic benefit of each scenario when compared with the baseline scenario RVC. The scenario with the higher value of $\Delta$ corresponds to the best economic alternative and represents the priority implementation scenario.

In case of similar economic benefits between the three alternative scenarios and correspondent IRC, ERC and RC, a prioritization criterion has been defined.

The prioritized criterion corresponds to the IRC of the surplus, due to its direct impacts on the raw material inputs reduction, minimizing the transport needs, and reducing the company dependency on other entities. Then the ERC, where the surplus can be reintro- 
duced in other production processes and be valued by various industries. RC, will not create an added value from the original material and therefore the last advisable valorization process, considering the surplus potential. To support the surplus potential analysis and their implementation, it is necessary to identify the internal and external factors that can influence its implementation. For this, a SWOT analysis should be carried out.

\section{SWOT Analysis}

In this last module, the gathered information enables the identification of the internal strengths and weaknesses of the company, as well as, the external opportunities and threats, as depicted in Figure 6. It is fundamental to identify and characterize the main factors that enable or constrain the implementation of IS in the company, to support the stakeholders identifying the major barriers and defining the priority actions, to further implement the symbiotic practices.

\section{SWOT Analysis}

$\checkmark$

Internal Potential

- Strengths

- Weaknesses

\section{External Potential}

- Opportunities

- Threats

Figure 6. SWOT Analysis-Internal and External potential.

The SWOT module considers six different fields of study, which are associated with the major barriers against the implementation of symbiotic exchanges. Those fields were defined as Management, Economic, Logistics, Technology, Human Resources, Environmental Management, and Legal.

To simplify the SWOT analysis, a set of questions has been created for each field with a single answer Yes/No. An answer Yes represents a strength (internal perspective), or an opportunity (externa perspective). While a No represents a weakness (internal perspective) or a threat (external perspective). The six fields in this study have been divided by an internal and external analysis, their technical objectives and its respective questions are detailed below in Tables 5 and 6 .

Table 5. Internal potential fields and their respective technical objectives.

\begin{tabular}{cll}
\hline Field & \multicolumn{1}{c}{ Technical Objective } & \multicolumn{1}{c}{ Question } \\
\hline Management & $\begin{array}{l}\text { Analyze the corporate willingness for IS } \\
\text { implementation }\end{array}$ & $\begin{array}{l}\text { Is the company willing to implement } \\
\text { IS processes? }\end{array}$ \\
\hline Economic & $\begin{array}{l}\text { Analyze the economic capacity of the company } \\
\text { for IS implementation }\end{array}$ & $\begin{array}{l}\text { Does the company have its own financial } \\
\text { resources for the implementation of } \\
\text { IS processes? }\end{array}$ \\
\hline Logistics & $\begin{array}{l}\text { Check if the company has already } \\
\text { implemented a logistical network }\end{array}$ & $\begin{array}{l}\text { Is there already a logistical network } \\
\text { implemented for the gathering and treatment } \\
\text { of the surplus? }\end{array}$ \\
\hline Technology & $\begin{array}{l}\text { Analyze the technological capacity of } \\
\text { the company }\end{array}$ & $\begin{array}{l}\text { Does the technology associated to the } \\
\text { productive processes allow the gathering of } \\
\text { their data? }\end{array}$ \\
\hline Human Resources & $\begin{array}{l}\text { Analyze the technical capacity of the } \\
\text { company's workers }\end{array}$ & $\begin{array}{l}\text { Is there anyone from the company staff with } \\
\text { experience in the valorization of surplus in } \\
\text { industrial processes? }\end{array}$ \\
\hline Environmental Management & $\begin{array}{l}\text { Analyze the existence of an environmental } \\
\text { plan of action in the company }\end{array}$ & $\begin{array}{l}\text { Is there a Plan of Action which focuses on the } \\
\text { valorization of the surplus? }\end{array}$ \\
\hline
\end{tabular}


Table 6. External potential fields and their respective technical objectives.

\begin{tabular}{cll}
\hline Field & \multicolumn{1}{c}{ Technical Objective } & \multicolumn{1}{c}{ Question } \\
\hline Management & $\begin{array}{l}\text { Identify possible IS relations with } \\
\text { external entities }\end{array}$ & $\begin{array}{l}\text { Was the company ever engaged in an IS program, whether by an } \\
\text { I\&D entity, consulting agency, research center or university? }\end{array}$ \\
\hline Economical & $\begin{array}{l}\text { Identify financing sources } \\
\text { (local/national/European) }\end{array}$ & $\begin{array}{l}\text { Does the company know of any existing funds/measures to } \\
\text { promote the implementation of IS processes? }\end{array}$ \\
\hline Logistical & $\begin{array}{l}\text { Identify the logistical context to support a } \\
\text { potential symbiosis }\end{array}$ & Are there other neighboring companies in the industrial area? \\
\hline Technological & $\begin{array}{l}\text { Identify previous IS implementation in } \\
\text { the industrial area }\end{array}$ & $\begin{array}{l}\text { Does the company know if any neighboring company exchanges } \\
\text { surplus with other companies? }\end{array}$ \\
\hline \multirow{2}{*}{ Legal } & $\begin{array}{l}\text { Identify the existence legal framework } \\
\text { supporting or hindering the } \\
\text { implementation of symbiotic processes }\end{array}$ & $\begin{array}{l}\text { Does the company know of any regulation/project that supports } \\
\text { the implementation of IS in its area? }\end{array}$ \\
\hline
\end{tabular}

The evaluation questionnaire was created according to the technical objective associated with each field. The qualitative information gathered in this questionnaire allows companies to identify their main barriers and enabling their potential for IS implementation.

Once the three sequential modules are implemented, it is possible to define the current state of the company and their key intervention areas, identify the best valorization alternative for the surplus, from an economic perspective, and compile the positive and negative factors that can influence the scenario implementation. All these modules are crucial to help the stakeholder defining the strategy to implement IS practices.

\section{Discussion}

The concept of potential for IS can take different approaches. While in the literature it is mainly being assessed at a regional level, for clustered networks or Eco-Industrial Parks, the potential for IS in the developed tool comprehends a new concept that covers the company framework, materials, and context. This concept aims to establish a new multicriteria perspective, more comprehensive and complete, considering the whole symbiotic process phases.

The existing approaches to determine the potential for IS are limited to the identification of symbiotic opportunities based on materials and surpluses, with its main focus on the development of procedures for matching and mimicking of synergies, not considering the integration with the company reality and its context $[25,44]$.

The present study produced a schematic identification framework of the inputs and outputs of materials and surpluses as well as an integrated identification of the potential scenarios involved in the symbiotic processes.

The developed modules were developed to be complementary with each other and express an innovative approach when compared to other tools, by the analysis of the complete symbiotic process.

The identification module gathers relevant information for the company characterization in a symbiosis context and is the base for the following modules. The location will support future logistic decisions, the activity code will facilitate the search of potential synergies in existing sectorial databases, the company size will be important to define available funding and the environmental practices to establish the company commitment on environmental issues. This information is a crucial component for the surplus potential and to validate via crosscheck the information from the SWOT analysis.

The current state aims to analyze the monitoring level on materials and surpluses flow to establish improvement areas and promote resource efficiency, to potentially prioritize actions and identify the current processes associated to the surpluses' management. The presence of current symbiotic processes allows its optimization and diversification on Module $\mathrm{C}$ while the absence of these processes directs the company to the beginning of the scope activities. The current state quantitative results facilitate the continuous improvement 
and the company periodic performance revaluation regarding materials and surpluses control and waste management processes.

Regarding the implementation potential, the valorization scenarios they were not limited to the identification of synergies but developed to support decision making by economic costs perspective comparison. Once defined the economic potential dimension of the surplus, it is essential to characterize the main factors that might positively or negatively influence the symbiotic process implementation. The SWOT analysis perform a non-material context analysis of the symbiotic process complementary to the previously developed modules, allowing to accurately and expeditiously identify the key factors that might affect the valorization implementation scenarios.

The flexible character of the tool, allows to receive data from available synergy identification tools, to facilitate scenarios diversification and support further comparison. Tools such as LCA and PEF could be complementarily used to support the decision-making of the most environmentally sound alternative, and considering the whole life cycle of the product as referred in [4].

The IS potential assessment methodology derived from the study is currently under test and validation in some industries of the metalworking and retail sectors. Although the final results are not yet available, preliminary interaction with the companies attest the applicability to support them in three main fields: the identification of the main barriers to the implementation process that have to be addressed and considered by management level of the company; the support of internal decision making by reevaluation of implemented scenarios and simulation of potential alternatives based on cost perspective; the possibility to implement a continuous improvement performance at short, medium and long term strategy based on the actual state diagnosis module.

In case that the full set of scenarios defined for further comparison are not defined, its identification is highly dependent on background research.

The present tool is still not digitally integrated with complementary tools for synergy identification and cost assessment, resulting on a higher time-consuming process.

\section{Conclusions}

The presented tool demonstrates an innovative character, due to its unique methodological sequential approach regarding the assessment of the preliminary conditions of a company towards engaging in IS.

A dedicated logical framework and practical assessment tools, including data acquisition methods introduces an innovative concept for IS potential assessment by covering three different stages. The first regarding the actual practices and monitoring level on material flows and the implemented surplus management scenarios, the second focused on the comparison between different scenarios of surplus' valorization based on a cost perspective analysis, and finally a complementary evaluation on the internal and external factors that can significantly influence the full process implementation.

The present tool allows to identify inefficiencies regarding material flows and surpluses management practices, facilitating the implementation of corrective actions and periodic performance assessments with a view to continuous improvement.

The characterization of the existing valorization alternatives based on their economic costs and their subsequent comparison, allows to support companies in decision making and simulation processes on the best scenarios from a cost benefit perspective.

The simplified identification of key internal and external factors associated to most relevant barriers on IS processes implementation allows the company to complement qualitatively their cost-benefit decision-making process analysis.

There is a high dependence on the reliability of data provided by industrials as well as the availability of data for the assessment of costs for new valorization scenarios. To assess the costs of alternatives scenarios implementation the stakeholder needs to estimate this value within external entities, in order to simulate and further compare with the different 
alternatives. However, in case of data unavailability, approximations on final expected costs can be necessary to overcome the lack and accuracy of data.

Another barrier which could extend or hinder the tool application is the lack of surplus' categorization as by-product or residue, that can lead to an additional research activities. This classification is highly dependent on the implementation context and has to be considered. Moreover, the implementation records assessment is supported by available databases or existing documentation, nevertheless it could limit the potential for surplus scenarios identification in case of lack of recorded information publicly available.

The inclusion of environmental and social impacts in the final costs' comparison will actively contribute to a more accurate decision making on the prioritization of the best scenarios.

The tool was designed to be applied in any industrial sectors and available surpluses, further validation in different sectors should be performed at project and implementation levels. Although, the standardization of this tool could be highly dependent on the legal national context, due to the different legislation regarding the surplus disposal and valorization. The full digitalization of the tool and the integration with intersectoral synergy databases, identification tools and cost calculation should be addressed in further research. A final cost-benefit viability analysis study and a suitable business model for the best scenario is recommended.

Author Contributions: Conceptualization, J.A., C.A., R.D., and F.C.; investigation, I.F., R.D. and J.H.; methodology, J.A., B.M. and J.H.; project administration, C.A.; resources, J.H.; writing-original draft, I.F., J.A. and R.D.; writing—review and editing, C.A., B.M. and M.I. All authors have read and agreed to the published version of the manuscript.

Funding: This work has been funded by the European Regional Development Fund (FEDER) through a grant of the Operational Programme for Competitivity and Internationalization of Portugal 2020 Partnership Agreement (PRODUTECH-SIF, POCI-01-0247-FEDER-024541).

Acknowledgments: The authors would like to thank the reviewers for the comments and suggestions which helped to improve the current work.

Conflicts of Interest: The authors declare no conflict of interest.

\section{References}

1. Chertow, M.R. Industrial Symbiosis: Literature and Taxonomy. Annu. Rev. Energy Environ. 2000, 25, 313-337. [CrossRef]

2. CEN-CENELEC Industrial Symbiosis: Core Elements and Implementation Approaches. Available online: https://www. cencenelec.eu/research/CWA/Pages/default.aspx (accessed on 3 September 2020).

3. Domenech, T.; Bleischwitz, R.; Doranova, A.; Panayotopoulos, D.; Roman, L. Mapping Industrial Symbiosis Development in Europe_typologies of networks, characteristics, performance and contribution to the Circular Economy. Resour. Conserv. Recycl. 2019, 141, 76-98. [CrossRef]

4. Marrucci, L.; Daddi, T.; Iraldo, F. The integration of circular economy with sustainable consumption and production tools: Systematic review and future research agenda. J. Clean. Prod. 2019, 240, 118268. [CrossRef]

5. Lombardi, R. Non-technical barriers to (and drivers for) the circular economy through industrial symbiosis: A practical input. Econ. Policy Energy Environ. 2017, 171-189. [CrossRef]

6. Golev, A.; Corder, G.D.; Giurco, D.P. Barriers to Industrial Symbiosis: Insights from the Use of a Maturity Grid. J. Ind. Ecol. 2015, 19, 141-153. [CrossRef]

7. Islam, K. Industrial Symbiosis: A Review on Uncovering Approaches, Opportunities, Barriers and Policies. J. Civ. Eng. Environ. Sci. 2016, 2, 011-019. [CrossRef]

8. Vladimirova, D.; Miller, K.; Evans, S. Lessons Learnt and Best Practices for Enhancing Industrial Symbiosis in the Process Industry. Available online: https: / www.scalerproject.eu/wp-content/uploads/2019/01/Report-Industrial-Symbiosis-Best-PracticesH2020-SCALER.pdf (accessed on 6 October 2020).

9. Henriques, J.; Estrela, M.; Ascenço, C.; Azevedo, J.; Dias, R. Scaler Deliverable 2.3: How to Create Incentives for Industrial Symbiosis; 2019. Available online: https:/ / www.scalerproject.eu/wp-content/uploads/2019/07/Incentives-assessment-ReportSCALER-D2.3.pdf (accessed on 16 October 2020).

10. Henriques, J.; Azevedo, J.; Dias, R.; Estrela, M.; Ascenço, C. Industrial Symbiosis Incentives: Mitigating Risks for Facilitated Implementation. Zenodo 2020. [CrossRef]

11. Neves, A.; Godina, R.; Azevedo, S.G.; Pimentel, C.; Matias, J.C.O. The Potential of Industrial Symbiosis: Case Analysis and Main Drivers and Barriers to Its Implementation. Sustainability 2019, 11, 7095. [CrossRef] 
12. Sharib, S.; Halog, A. Enhancing value chains by applying industrial symbiosis concept to the Rubber City in Kedah, Malaysia. J. Clean. Prod. 2017. [CrossRef]

13. Isenmann, R.; Chernykh, K. The role of ICT in industrial symbiosis projects-Environmental ICT applications for eco-industrial development. In Environment Informatics Industrial Environment Protection Concepts, Methods Tools; EnviroInfo: Berlin, Germany, 2009.

14. Lawal, M.; Wan Alwi, S.R.; Manan, Z.A.; Ho, W.S. Industrial symbiosis tools-A review. J. Clean. Prod. 2021, $280,124327$. [CrossRef]

15. Marrucci, L.; Marchi, M.; Daddi, T. Improving the carbon footprint of food and packaging waste management in a supermarket of the Italian retail sector. Waste Manag. 2020, 105, 594-603. [CrossRef]

16. Boix, M.; Montastruc, L.; Azzaro-Pantel, C.; Domenech, S. Optimization methods applied to the design of eco-industrial parks: A literature review. J. Clean. Prod. 2015. [CrossRef]

17. Kastner, C.A.; Lau, R.; Kraft, M. Quantitative tools for cultivating symbiosis in industrial parks; a literature review. Appl. Energy 2015. [CrossRef]

18. Johnsen, I.; Berlina, A.; Lindberg, G.; Mikkola, N.; Smed Olsen, L.; Teräs, J. The Potential of IS as a Key Driver of Green Growth in Nordic. Available online: https:/ / www.diva-portal.org/smash/get/diva2:875756/FULLTEXT01.pdf (accessed on 6 October 2020).

19. Daddi, T.; Nucci, B.; Iraldo, F. Using Life Cycle Assessment (LCA) to measure the environmental benefits of industrial symbiosis in an industrial cluster of SMEs. J. Clean. Prod. 2017. [CrossRef]

20. Daddi, T.; Nucci, B.; Iraldo, F.; Testa, F. Enhancing the adoption of life cycle assessment by small and medium enterprises grouped in an industrial cluster: A case study of the tanning cluster in Tuscany (Italy). J. Ind. Ecol. 2016, 20, 1199-1211. [CrossRef]

21. Stone, J.; Garcia-Garcia, G.; Rahimifard, S. Development of a pragmatic framework to help food and drink manufacturers select the most sustainable food waste valorisation strategy. J. Environ. Manag. 2019, 247, 425-438. [CrossRef] [PubMed]

22. European Comission. Communication from the Commission to the European Parliament, the Council, the Economic and Social Committee and the Committee of the Regions. On the Sustainable Consumption and Production and Sustainable Industrial Policy Action Plan; COM 397 final; European Comission: Brussels, Belgium, 2014.

23. Maqbool, A.S.; Alva, F.M.; Van Eetvelde, G. An assessment of European information technology tools to support industrial symbiosis. Sustainability 2018, 11, 131. [CrossRef]

24. Cecelja, F.; Raafat, T.; Trokanas, N.; Innes, S.; Smith, M.; Yang, A.; Zorgios, Y.; Korkofygas, A.; Kokossis, A. E-Symbiosis: Technology-enabled support for Industrial Symbiosis targeting Small and Medium Enterprises and innovation. J. Clean. Prod. 2015, 98, 336-352. [CrossRef]

25. Yeo, Z.; Masi, D.; Low, J.S.C.; Ng, Y.T.; Tan, P.S.; Barnes, S. Tools for promoting industrial symbiosis: A systematic review. J. Ind. Ecol. 2019, 23, 1087-1108. [CrossRef]

26. Produtech Sif. Available online: http:/ / mobilizadores.produtech.org/en/produtech-sif (accessed on 3 October 2020).

27. Röbel, S.; Emrich, A.; Klein, S.; Loos, P. A maturity model for business model management in industry 4.0. In Proceedings of the MKWI 2018-Multikonferenz Wirtschaftsinformatik, Lüneburg, Germany, 6-9 March 2018; pp. 2031-2042.

28. van Looy, A.; Poels, G.; Snoeck, M. Evaluating business process maturity models. J. Assoc. Inf. Syst. 2017, 18, 461-486. [CrossRef]

29. Barra, G.M.J.; Ladeira, M.B. Modelo de maturidade para processos de certificação no sistema agroindustrial do café. REGE—Rev. Gestão 2017, 24, 134-148. [CrossRef]

30. Ibbs, C.W.; Kwak, Y.H. Assessing Project Management Maturity. Proj. Manag. J. 2000, 31, 32-43. [CrossRef]

31. Andersen, E.S.; Jessen, S.A. Project maturity in organisations. Int. J. Proj. Manag. 2003, 21, 457-461. [CrossRef]

32. Valadares De Oliveira, M.P.; Ladeira, M.B.; Mccormack, K.P. The Supply Chain Process Management Maturity Model-SCPM3. Supply Chain Manag. Pathw. Res. Pract. 2011, 201-218. [CrossRef]

33. Neto, B.; Kroeze, C.; Hordijk, L.; Costa, C.A. Selecting Industrial Ecology Tools: Strengths and Weaknesses for Use in a Decision Support Tool. Available online: https:/ / repositorio-aberto.up.pt/handle/10216/15836 (accessed on 28 January 2021).

34. Lütje, A.; Wohlgemuth, V. Requirements Engineering for an Industrial Symbiosis Tool for Industrial Parks Covering System Analysis, Transformation Simulation and Goal Setting. Adm. Sci. 2020, 10, 10. [CrossRef]

35. Sheppard, P.; Garcia-Garcia, G.; Stone, J.; Rahimifard, S. A complete decision-support infrastructure for food waste valorisation. J. Clean. Prod. 2020, 247, 119608. [CrossRef]

36. Ghazinoory, S.; Abdi, M.; Azadegan-Mehr, M. Swot Methodology: A State-of-the-Art Review for the Past, A Framework for the Future. J. Bus. Econ. Manag. 2011, 12, 24-48. [CrossRef]

37. Helms, M.M.; Nixon, J. Exploring SWOT analysis-Where are we now?: A review of academic research from the last decade. J. Strateg. Manag. 2010, 3, 215-251. [CrossRef]

38. Neves, A.; Godina, R.; Azevedo, S.G.; Matias, J.C.O. Current status, emerging challenges, and future prospects of industrial symbiosis in Portugal. Sustainability 2019, 11, 5497. [CrossRef]

39. ISDATA. The Industrial Symbiosis Data Repository. Available online: http:/ / isdata.org/ (accessed on 23 September 2020).

40. SCALER. Scaling European Resources with Industrial Symbiosis. Available online: https://www.scalerproject.eu/ (accessed on 23 September 2020).

41. MAESTRI. Available online: https:/ / maestri-spire.eu/ (accessed on 23 September 2020). 
42. Dias, R.; Azevedo, J.; Ferreira, I.; Estrela, M.; Henriques, J.; Ascenço, C.; Iten, M. Technical viability analysis of industrial synergies-an applied framework perspective. Sustainability 2020, 12, 7720. [CrossRef]

43. Schmidt, M.; Nakajima, M. Material flow cost accounting as an approach to improve resource efficiency in manufacturing companies. Resources 2013, 2, 358-369. [CrossRef]

44. Grant, G.B.; Seager, T.P.; Massard, G.; Nies, L. Information and communication technology for industrial symbiosis. J. Ind. Ecol. 2010, 14, 740-753. [CrossRef] 